\title{
Posterior Excision of Hemivertebrae; The Presence of a Hemilamina may be Misleading
}

\author{
Alexander David Laing Baker ${ }^{1}$, Leanne Elizabeth Dupley ${ }^{1}$, Michael John Gibson ${ }^{2}$ and James Thomas Bourne ${ }^{1 *}$ \\ ${ }^{1}$ Department of Trauma \& Orthopaedic Surgery, Royal Preston Hospital, United Kingdom
}

${ }^{2}$ Department of Orthopaedics, Freeman Hospital, UK

Submission: February 07, 2018; Published: March 09, 2018

*Corresponding author: James Thomas Bourne, Lancashire Teaching Hospitals NHS Foundation Trust, Department of Trauma \& Orthopaedic Surgery, Royal Preston Hospital, Shared Green Lane, Fulwood, Preston, Lancashire, PR2 9HT, United Kingdom, Email: james.bourne@lthtr.nhs.uk

\begin{abstract}
Study design: An observational study in patients with congenital spinal deformity.

Objective: To review the relationship between hemivertebrae and the posterior spinal elements in congenital spinal deformity.

Summary of background data: The vertebral body anomalies of congenital scoliosis have been classified and are well known. More recently a variety of posterior element anomalies have been identified. The relationship between posterior and anterior structures is important when posterior excision of a hemivertebrae is undertaken
\end{abstract}

Methods: Patients recorded as having congenital spinal deformity were identified from a database. All available imaging was obtained and reviewed with particular reference to posterior element anatomy as visualised on CT or MRI scans.

Results: In total 36 patients with congenital spinal deformity were identified and their imaging was reviewed. 24 patients were identified with hemivertebrae. Clear images were obtained of the posterior elements in 18 cases. 9 isolated hemilaminae (as visualised on coronal CT or MRI) were seen in 8 patients with associated hemivertebrae. In 7 of 9 cases the hemilamina was found to be one level cranial to the hemivertebrae and in the remaining case it was at the same level.

Conclusion: When a posterior approach is used to excise a hemilamina, care should be taken to avoid wrong level surgery. A pre-operative assessment with a CT scan may be helpful.

Keywords: Scoliosis; Congenital scoliosis; Congenital deformity; Hemivertebra; Hemilamina

\section{Introduction}

Congenital scoliosis is a lateral curvature of the spine that results from the differing growth potential of vertebral anomalies present at birth. It can lead to severe progressive spinal deformity. The different types of vertebral body anomaly that are associated with congenital scoliosis have been classified based on the appearance of plain radiographs [1-3]. No treatable cause for the vertebral anomalies that result in congenital scoliosis has been identified. Predictions can be made about the severity of the resultant spinal deformity based on classification of the anomalies present, and a knowledge of their natural history [1,4]. Decisions regarding surgical treatment are based on knowledge of the natural history and likely resultant deformity.

When a progressive scoliosis is seen in association with a hemivertebra, surgical excision can yield excellent results. Different surgical approaches for excision of a hemivertebra have been described. These include anterior, combined anterior and posterior approaches, and more recently an entirely posterior approach [5]. When undertaking excision of a congenital hemivertebra using a posterior approach prior knowledge of the bony anatomy of the posterior elements is useful. Recently three-dimensional CT scans have been used to classify the posterior element anomalies seen in association with congenital scoliosis [6]. The relationship between anterior and posterior anomalies in congenital scoliosis has not been well established. The following observational study reports on the anatomical relationship between hemivertebra and hemilamina seen in congenital scoliosis.

\section{Materials and Methods}

Institutional R\&D Approvals Committee permission was granted for the retrospective, anonymised use of prospectively gathered data. Patients or their legally authorised representative 
gave verbal permission for data and anonymised images to be used. Data were collected prospectively on patients attending our unit with spinal deformity. A database search was undertaken to identify all patients with congenital scoliosis seen in our unit over a period of 5 years. To determine the bony anatomy, all available imaging was reviewed independently by two orthopaedic spinal surgeons. There was no disagreement between the findings. Intra-observer difference was not assessed because of the low number of cases. Posterior element anatomy was classified according to the system used by Nakajima et al. [6].

\section{Results}

Between 2004 and 2009, 36 patients with congenital spinal deformity had been reviewed. A variety of congenital spinal anomalies were seen including: Fully segmented hemivertebrae (29 in 24 patients), semi-segmented hemivertebrae (6 in 5 patients), hemivertebrae with contralateral unsegmented bars ( 2 in 2 patients) and block vertebrae ( 2 in 2 patients). Curve magnitude ranged from 10 deg to 110 as measured on plain radiographs using the Cobb angle. 15 were male and 21 female. A variety of posterior element anomalies were also seen including, but not confined to, fully segmented, semi-segmented, and spina-bifida type hemilaminae.

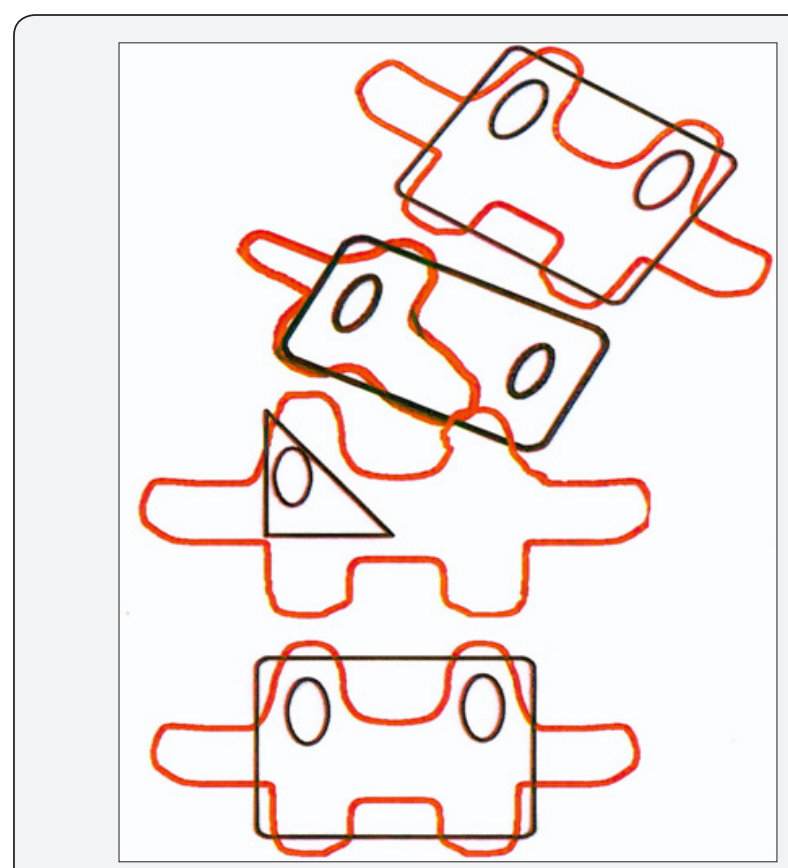

Figure 1: Diagram of hemilamina (red) cephalad to the hemivertebra (black).

Imaging of sufficient quality to define posterior element anatomy was available in 18 of 24 patients with 1 or more segmented hemivertebrae. Of these 18 patients, 10 had either a spina bifida type lamina or bilamina. The remaining eight patients had 9 hemilamina with an associated hemivertebra demonstrated on coronal CT (7 patients) and coronal MR (1 patient). In 7 of these 9 cases (78\%) the hemilamina was found to be one level cranial to the hemivertebrae (Figure 1) and in the remaining 2 cases the hemilamina was at the same level as the hemivertebra (Figure 2). In no case was a hemilamina identified at a level caudal to the associated hemivertebra.

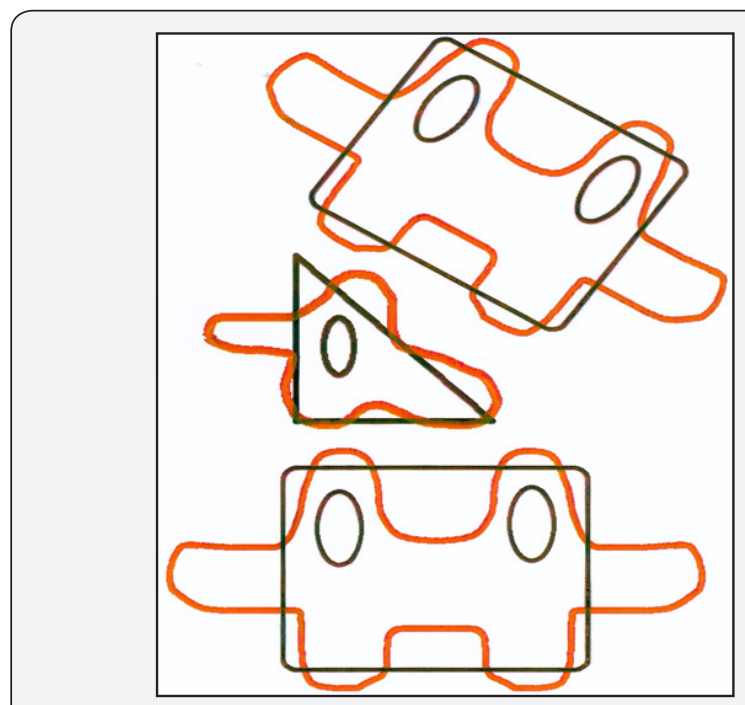

Figure 2 : Diagram of hemilamina (red) at the same level as hemivertebra (black).

\section{Imaging}

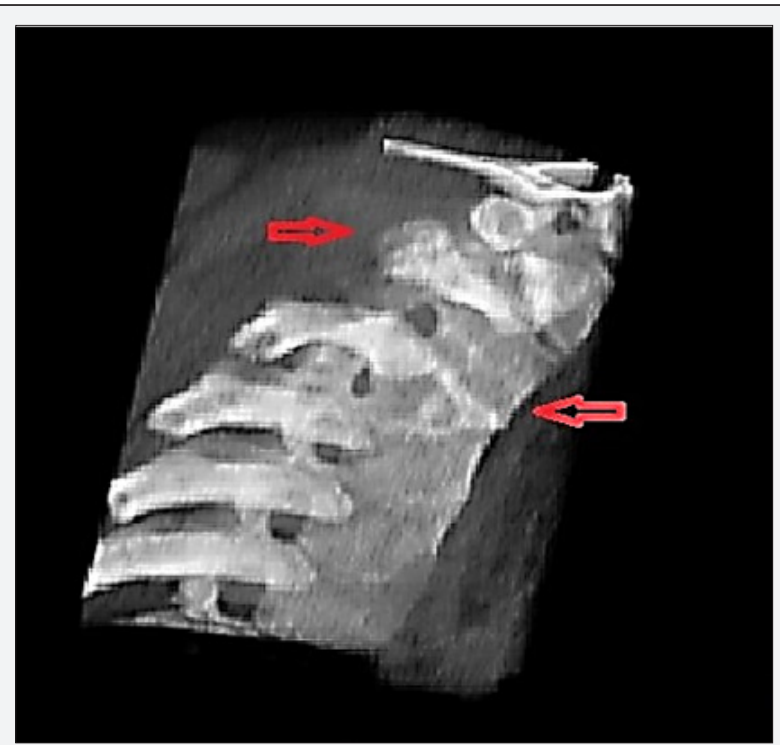

Figure 3 : A 3D topographical CT image. Arrows point to the hemivertebra anteriorly and missing posterior structures one level cephalad.

Different techniques including plain radiographs, computed tomography and magnetic resonance imaging, have been used to assess the anatomy of congenital scoliosis. More recently 'Digital Picture Archiving and Communication Systems' (PACS) have become more common. These systems typically allow the viewer to scroll through sequential images in a dynamic manner. This allows for the relationships between structures to be better traced than when comparing images side by side. In this study sequential coronal CT images viewed in this way were found to 
give the best impression of the relationship between anterior and posterior structures. Alternatively topographical 3D images can be used. However, the precise oblique orientation required to enable the viewer to see both anterior hemivertebra and the posterior hemilamina thus establishing the relationship can be difficult to achieve and often requires the viewer to rotate the 3D image and trace the structures in a similarly dynamic way.

3D example (Figures 3-5).
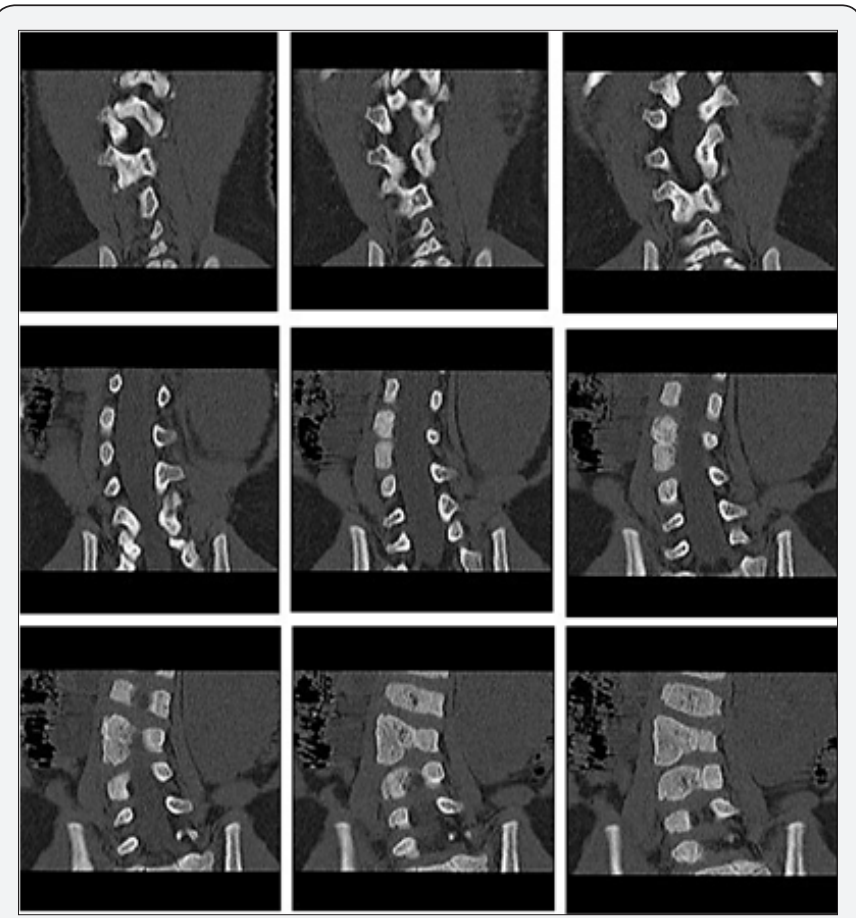

Figure 4 : Coronal CT example 1.
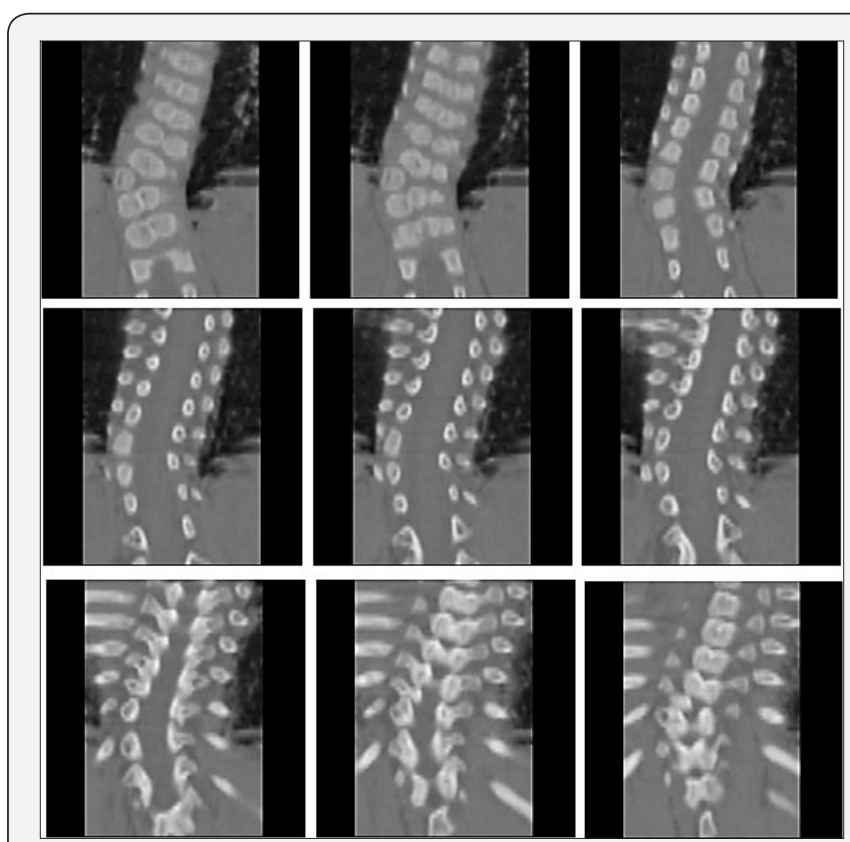

Figure 5 : Coronal CT example 2.

\section{Discussion}

The observation in this study that hemilamina frequently occur ( 7 of $9,78 \%$ ) one level cephalad to the associated anterior hemivertebrae should alert surgeons undertaking posterior excision of a hemivertebrae to take care to avoid wrong level surgery. It is rarely possible to establish a relationship between anterior and posterior structures using plain radiographs. Preoperative CT scanning allows the sequential viewing of coronal images allowing the relationship between anterior and posterior structures to be traced.

\section{Embryology}

The segmental nature of human embryonic development is well established [7]. Vertebrae (and intervertebral discs) develop from somites which form in a cranial to caudal sequence. Somites give rise to cartilaginous precursors that subsequently ossify. The structure of the fully developed vertebrae is determined at an early (mesenchymal) stage of intrauterine development [8]. Abnormalities of formation or segmentation that lead to congenital vertebral anomalies may occur either at the mesenchymal stage or during the ossification process. Ossification of the cartilaginous precursor usually develops from a single centrum. When two ossification centres are present one may fail to develop leading to a hemivertebra, a process which has been linked to the development of a blood supply $[9,10]$.

The exact mechanism by which vertebrae arise from somites has yet to be fully established. However, it has been proposed that the posterior elements of a vertebra develop from a single somite, whereas the developing vertebral body undergoes a process of re-segmentation (metameric shift) [7]. This resegmentation results in a vertebral body that comprises cells from adjacent somites. One somite contributes to the upper and lower halves of adjacent vertebral bodies and the intervertebral disc. Furthermore, the rudimentary posterior elements appear to develop from the caudal half of the sclerotome (from the ventral somite) which may be associated with the half of the somite which (following re-segmentation) will become the vertebral body one level caudal. The re-segmentation of the developing vertebral body and the observation that a hemilamina may be associated with a hemivertebra one level more caudal would allow a theory that suggests a single aetiological event causing both anomalies within the developing somite.

\section{Conclusion}

It is not possible from the observations presented here to confirm or refute a predictable relationship between anterior and posterior structures in congenital scoliosis where the hemilamina is found one level cephalad to the hemivertebra or at the same level. However, the observations made should serve to highlight the importance of identifying the correct bony anatomy before when undertaking posterior excision of congenital hemivertebrae. 


\section{Conflict of Interest}

The Authors declare that there is no conflict of interest.

\section{References}

1. McMaster MY, Ohtsuka K (1982) The natural history of congenital scoliosis. A study of two hundred and fifty-one patients. J Bone Joint Surg Am 64: 1128-1147.

2. Winter RB, Moe JH, Eilers VE (1968) Congenital Scoliosis. A Study of 234 Patients Treated and Untreated. Part I: Natural History. J Bone and Joint Surg Am 50-A: 1-15.

3. Nasca RJ, Stelling FH, Steel HH (1975) Progression of Congenital Scoliosis Due to Hemivertebrae and Hemivertebrae with Bars. J Bone and Joint Surg Am 57-A: 456-466.

4. McMaster MJ, Singh H (1999) Natural history of congenital kyphosis and kyphoscoliosis. A study of one hundred and twelve patients. J Bone Joint Surg Am 81: 1367-1383.
5. Ruf M, Harms J (2002) Hemivertebra Resection by a Posterior Approach. Innovative operative Tachnique and First Results. Spine 27(10): 1116-1123.

6. Nakajima A, Kawakami N, Imagama S, Tsuji T, Goto M, et al. (2007) Three-Dimensional Analysis of Formation Failure in Congenital Scoliosis. Spine 32(5): 562-567.

7. Christ B, Wilting J (1992) From somites to vertebral column. Annals of Anatomy 174: 23-32.

8. Kieny M, Mauger A, Sengel P (1927) Early regionalization of the somatic mesoderm as studied by the development of the axial skeleton of the chick embryo. Develop Biol 28(1): 142-161.

9. Tanaka T, Uhthoff HK (1981) The pathogenesis of congenital vertebral malformations: a study based on observations made in 11 human embryos and fetuses. Acta Orthop Scand 52(4): 413-425.

10. Tsou PM, Yau A, Hodgson AR (1980) Embryogenesis and prenatal development of congenital vertebral anomalies and their classification. Clin Othop Relat Res 152: 211-231.

\section{Your next submission with Juniper Publishers will reach you the below assets}

- Quality Editorial service

- Swift Peer Review

- Reprints availability

- E-prints Service

- Manuscript Podcast for convenient understanding

- Global attainment for your research

- Manuscript accessibility in different formats

( Pdf, E-pub, Full Text, Audio)

- Unceasing customer service

Track the below URL for one-step submission https://juniperpublishers.com/online-submission.php 